\title{
Concentração de íons flúor em águas minerais envasadas no Rio Grande do Sul
}

\section{Concentration of fluoride ions in mineral water bottled in the state of Rio Grande do Sul}

Alexandre Emidio Ribeiro da Silva* Francisco Roberto de Avelar Bastos**

Mariana Silveira Echeverria*** Jiuliani Radünz $z^{* * *+}$

Camila Reis de Oliveira ${ }^{* * * * *}$

Celso Afonso Klein-Junior*

\section{Resumo}

Objetivo: avaliar o nível de flúor presente nas águas minerais carbogasosas e não carbogasosas envasadas no estado do Rio Grande do Sul, comparando os dados com as informações descritas nos rótulos das embalagens. Materiais e método: foram analisadas cinco marcas comerciais de água mineral. Os valores de padrão/ amostra e tampão Tisab foram utilizados em uma relação de 1:1, e as amostras foram lidas em duplicata. As amostras carbogasosas foram agitadas com bastão magnético para eliminação do gás carbônico. Para determinação de flúor, foram utilizados analisador específico de íons, eletrodo seletivo para íon flúor, eletrodo de referência $\mathrm{Ag} / \mathrm{AgCl}$ de junção simples. Resultados: foram encontradas concentrações de flúor variando entre $0,13 \mathrm{mg} \mathrm{F}-/ \mathrm{L}$ e $1,31 \mathrm{mg} \mathrm{F}-\mathrm{L}$, com diferenças entre os valores estipulados nos rótulos das marcas de água mineral avaliadas e as análises laboratoriais na presente investigação. Os valores de duas marcas de água mineral com flúor analisadas no estudo mostraram-se acima, considerando os valores de referência $(0,6-0,8 \mathrm{mg} \mathrm{F}-\mathrm{L} \mathrm{L})$, e uma marca não apresentou valores de ação preventiva contra a cárie dentária (valores abaixo de $0,6 \mathrm{mg} \mathrm{F} \%$ L). Conclusão: conclui-se que há divergência entre os valores de íons flúor encontrados nas medições e os informados nos rótulos, sendo necessário um sistema de melhor vigilância para o controle dos níveis de flúor nas águas minerais disponibilizadas à população do estado do Rio Grande do Sul, considerando os benefícios do consumo de águas minerais para prevenção dos níveis de cárie na população.

Palavras-chave: Águas minerais. Fluoretação. Vigilância sanitária.

\section{Introdução}

O uso do flúor apresenta grande importância no controle do desenvolvimento da cárie dentária, porque favorece a remineralização do esmalte dentário e interfere na formação e no mecanismo do biofilme microbiano ${ }^{1,2}$. A fluoretação das águas de abastecimento público foi uma das principais medidas de saúde pública, consagrada mundialmente para a prevenção da cárie dentária, sendo que estudos epidemiológicos confirmaram sua segurança e sua efetividade no controle da cárie dentária ${ }^{3-5}$.

A literatura tem descrito a importância de concentrações ideais de flúor $(0,6 \mathrm{mg} / \mathrm{L}$ a $0,8 \mathrm{mg} / \mathrm{L})$ para prevenção de cárie dentária ${ }^{6}$. Ao mesmo tempo em que baixas concentrações de flúor são ineficientes na prevenção da cárie dentária, as altas concentrações representam um risco para o aparecimento de fluorose dentária em crianças durante a formação do esmalte dentário. Esse defeito de desenvolvimento do esmalte é caracterizado por hipomineralização e maior porosidade da área abaixo da superfície do esmalte dentário 5 .

Além da água de abastecimento público, há outros métodos que liberam fluoreto e podem ser utilizados para a prevenção da cárie dentária, como dentifrícios, bochechos com colutórios fluoretados, produtos utilizados pelo profissional de odontologia e águas minerais com flúor ${ }^{7}$.

\footnotetext{
Doutor em Epidemiologia, Programa de Pós-Graduação em Odontologia, Universidade Federal de Pelotas, Pelotas, Brasil.

Doutor em Odontologia, Universidade Luterana do Brasil, Cachoeira do Sul, Brasil.

Cirurgiã-dentista, Programa de Pós-Graduação em Epidemiologia, Universidade Federal de Pelotas, Pelotas, Brasil.

*** Cirurgiã-dentista, Universidade Luterana do Brasil, Cachoeira do Sul, Brasil.

Química, Fundação de Ciência e Tecnologia do RS.

Pós-doutor em Biomateriais, Universidade Luterana do Brasil, Cachoeira do Sul, Brasil.
} 
Dos produtos que contêm flúor disponíveis para população, o consumo de água mineral envasada industrialmente tem aumentado muito nos últimos anos no Brasil ${ }^{8-10}$, visto que, em um estudo realizado no município de Bauru, SP, $29,7 \%$ da população relatou consumir água mineral ${ }^{8}$. As águas minerais são consideradas como aquelas que infiltraram no subsolo e seu conteúdo acumulou sais minerais, adquirindo novas características físico-químicas. A quantidade desses sais apresenta uma relação direta com o calor, pois as capacidades de dissolver minerais e incorporar solutos aumentam conforme a temperatura. Devido a esse fato, podem existir diferenças em termos de qualidade e quantidade de flúor presente nas águas minerais ${ }^{8}$.

Diante do aumento do consumo de água envasada e das diferenças que podem existir nas concentrações, é fundamental o controle da concentração de flúor presente nas águas minerais disponibilizadas no mercado. Portanto, o presente estudo tem por objetivo avaliar o nível de flúor encontrado nas águas minerais carbogasosas e não carbogasosas envasadas no estado do Rio Grande do Sul, comparando-o com a descrição do rótulo fornecida pelo fabricante. A hipótese do estudo é que não haverá diferença entre os níveis de flúor indicados nos rótulos fornecidos pelos fabricantes e os valores encontrados nas análises laboratoriais realizadas no presente estudo.

\section{Materiais e método}

\section{Seleção da amostra}

Foram analisadas cinco marcas de água mineral de $500 \mathrm{ml}$ produzidas e envasadas no Rio Grande do Sul, Brasil, adquiridas em estabelecimentos comerciais (supermercados) de grande circulação. Para cada marca de água, foram adquiridas seis garrafas de lotes diferentes, sendo três garrafas de água carbogasosa e três de não carbogasosa. As marcas analisadas foram: Sarandi, Charrua, Fonte Ijuí, Água da Pedra e Versant. Todas as águas minerais adquiridas estavam dentro do prazo de validade do fabricante.

\section{Informações dos rótulos}

Os dados referentes a marca da água mineral, capacidade de cada recipiente, número do lote, data da análise química realizada pelo fabricante, data de engarrafamento e validade dos produtos estão descritos na Tabela 1.

\section{Aquisição e camuflagem das amostras}

Todas as águas minerais foram adquiridas em quatro supermercados diferentes e em cidades diversas (Porto Alegre, Pelotas, Cachoeira do Sul, Ho- rizontina, Ijuí, Pântano Grande), mesmo quando se tratava da mesma marca. As águas minerais foram classificadas da seguinte maneira: $\mathbf{A}$ - Sarandi gaseificada; B - Sarandi não gaseificada; C - Charrua gaseificada; D - Charrua não gaseificada; $\mathbf{E}$ - Fonte Ijuí gaseificada; $\mathbf{F}$ - Fonte Ijuí não gaseificada; $\mathbf{G}$ Água da Pedra gaseificada; H - Água da Pedra não gaseificada; I - Versant gaseificada; J - Versant não gaseificada.

As amostras foram camufladas para cegamento do analisador, sendo que foram apagadas as identificações das tampas, com o uso de acetona e lixas, e removidos os rótulos de identificação das águas. A identificação com a letra correspondente, conforme classificação descrita anteriormente, foi colocada na tampa e na própria garrafa, bem como no verso do rótulo, os quais foram todos guardados. A única identificação da garrafa que permaneceu foi referente a carimbagem do número do lote e validade. Os produtos analisados foram mantidos em seus recipientes originais e abertos somente no dia da análise.

\section{Calibração}

O método utilizado para avaliação dos íons flúor é válido para concentrações superiores a $0,1 \mathrm{mg} / \mathrm{L}$. O preparo da solução tampão (Tisab II) é composto de água destilada, ácido acético glacial, cloreto de sódio, ácido 1,2-ciclohexileno diamino tetracético (DCTA) e hidróxido de sódio. O equipamento foi calibrado antes das análises com as soluções-padrão de fluoreto preparadas e analisadas com o aparelho potenciômetro aferido com padrões de 0,5, 1,0 e $10,0 \mathrm{ppmF}^{-}$. Foram pipetados valores iguais de padrão/amostra e o tampão Tisab II, em um Becker de polietileno de $100 \mathrm{ml}$, adicionados $20 \mathrm{ml}$ de amostra e $20 \mathrm{ml}$ da solução Tisab II, na proporção de 1:1.

As amostras carbogasosas, imediatamente após a abertura do recipiente, foram colocadas dentro de um copo de Becker, agitadas com um bastão magnético durante 15 minutos aproximadamente, para que o gás carbônico fosse eliminado. Quando o equilíbrio foi estabelecido, realizou-se a leitura da concentração de $\mathrm{mg} \mathrm{F} / \mathrm{L}$.

\section{Análise das amostras}

As amostras foram submetidas ao equipamento analisador específico de íons Orion 710A, bem como eletrodo seletivo para íon flúor (94-09- Orion) e eletrodo de referência $\mathrm{Ag} / \mathrm{AgCl}$ de junção simples (9001- Orion).

As amostras foram lidas em duplicata. A cada dez leituras, nova calibração era realizada. Todas as soluções, assim como as amostras envolvidas, apresentavam-se, no momento da análise, à temperatura de $23^{\circ} \mathrm{C}$. 


\section{Análise estatística}

Foram calculadas as concentrações médias e os intervalos de confiança (IC95\%) de íons flúor das cinco marcas de água mineral gaseificada e não gaseificada. Para a comparação das concentrações de flúor das amostras e os valores descritos nos rótulos, foi realizado o teste T de Student, com nível de significância de $5 \%(\mathrm{p}<0,05)$.

\section{Resultados}

Todas as cinco marcas de águas minerais analisadas traziam informações sobre a data de validade (02/09/2012 a 24/07/2013) e a concentração média de íons flúor. Duas marcas não informavam a data de engarrafamento.

A Tabela 1 descreve os valores médios e os seus intervalos de confiança (IC95\%) das concentrações de íons flúor que foram analisadas. Independente se a água era ou não gaseificada, a menor concentração de íons flúor encontrada foi para a marca Água da Pedra não gaseificada (média $=0,13$ IC95\% 0,11$0,14)$ e o maior valor foi para a água Sarandi gaseificada (média = 1,31 IC95\% 1,19-1,44).
Tabela 1 - Concentrações médias e intervalos de confiança (IC95\%) de íons flúor das cinco marcas de água mineral gaseificada e não gaseificada analisadas em laboratório pelo método de eletrodo, Brasil, 2017

\begin{tabular}{c|c|c}
\hline Marca & Gaseificação & $\begin{array}{c}\text { Concentração média de } \\
\text { íons flúor } \\
\text { Laboratorial } \\
(\mathrm{mg} \mathrm{F-/L)}-(\mathrm{IC} 95 \%)\end{array}$ \\
\hline Sarandi & Gaseificada & $1,31(1,19 ; 1,44)$ \\
Sarandi & Não gaseificada & $1,28(1,27 ; 1,30)$ \\
Charrua & Gaseificada & $1,13(-1,14 ; 3,39)$ \\
Charrua & Não gaseificada & $0,62(0,57 ; 0,67)$ \\
Fonte ljuí & Gaseificada & $0,79(0,71 ; 0,86)$ \\
Fonte ljuí & Não gaseificada & $0,92(0,75 ; 1,09)$ \\
Água da Pedra & Gaseificada & $0,15(0,14 ; 0,17)$ \\
Água da Pedra & Não gaseificada & $0,13(0,11 ; 0,14)$ \\
Versant & Gaseificada & $0,74(0,55 ; 0,97)$ \\
Versant & Não gaseificada & $0,76(0,55 ; 0,93)$ \\
\hline
\end{tabular}

Fonte: autores.

Na Tabela 2, são comparadas as concentrações médias de íons flúor analisadas com as informações especificadas nos rótulos das marcas avaliadas. Das cinco marcas, as águas: Sarandi gaseificada $(\mathrm{p}=0,051)$, Charrua gaseificada $(\mathrm{p}=0,296)$ e Fonte Ijuí não gaseificada $(p=0,826)$ não apresentaram diferenças estatísticas entre a leitura da análise e o rótulo. No entanto, ao não considerar se a água é gaseificada ou não, todas as marcas estudadas apresentaram diferenças estatísticas na comparação das análises realizadas em laboratório com as informações especificadas no rótulo.

Tabela 2 - Comparação das concentrações médias de íons flúor das cinco marcas de água mineral gaseificada e não gaseificada analisadas em laboratório pelo método de eletrodo, com as informações especificadas pelo fabricante, Brasil, 2017

\begin{tabular}{|c|c|c|c|c|}
\hline Marca & Gaseificação & $\begin{array}{l}\text { Concentração média de íons flúor } \\
\text { especificada no rótulo (mg F-/L) }\end{array}$ & $\begin{array}{l}\text { Concentração média de íons flúor } \\
\text { laboratorial (mg F-/L) }\end{array}$ & Valor $\mathrm{p}^{*}$ \\
\hline Sarandi & Gaseificada & 1,19 & 1,31 & 0,051 \\
\hline Sarandi & Não gaseificada & 1,19 & 1,28 & 0,001 \\
\hline Charrua & Gaseificada & 0,39 & 1,13 & 0,296 \\
\hline Charrua & Não gaseificada & 0,39 & 0,62 & 0,003 \\
\hline Fonte ljuí & Gaseificada & 0,93 & 0,79 & 0,016 \\
\hline Fonte ljuí & Não gaseificada & 0,93 & 0,92 & 0,826 \\
\hline Água da Pedra & Gaseificada & 0,06 & 0,15 & 0,003 \\
\hline Água da Pedra & Não gaseificada & 0,06 & 0,13 & 0,004 \\
\hline Versant & Gaseificada & 0,97 & 0,74 & 0,034 \\
\hline Versant & Não gaseificada & 0,97 & 0,76 & 0,005 \\
\hline
\end{tabular}

* Nível de significância de $5 \%$.

Fonte: autores. 


\section{Discussão}

A hipótese do presente estudo não foi comprovada, pois foram observadas diferenças estatísticas entre os níveis de flúor indicados nos rótulos pelos fabricantes e as análises laboratoriais realizadas no estudo. Entre as dez amostras de águas minerais analisadas neste estudo, sete apresentaram diferenças estatísticas entre as quantidades de flúor especificadas no rótulo pelo fabricante e os valores encontrados nas análises laboratoriais realizadas: Sarandi não gaseificada $(\mathrm{p}=0,001)$; Charrua não gaseificada $(p=0,003)$; Fonte Ijuí gaseificada $(\mathrm{p}=0,016)$; Água da Pedra gaseificada $(\mathrm{p}=0,003)$; Água da Pedra não gaseificada $(\mathrm{p}=0,004)$; Versant gaseificada $(\mathrm{p}=0,034)$; Versant não gaseificada $(p=0,005)$. As maiores médias de concentrações de íons fluoreto foram encontradas na água mineral Sarandi gaseificada $(1,31$ - IC 1,$19 ; 1,44)$ e na não gaseificada (1,28 - IC 1,27; 1,30), já as menores médias, na Água da Pedra não gaseificada $(0,13$ - IC $0,11 ; 0,14)$ e na gaseificada $(0,15$ - IC 0,$14 ; 0,17)$.

Houve uma discordância entre as concentrações de flúor impressas no rótulo e as verificadas com a análise laboratorial na maioria das amostras analisadas. Esse resultado é consistente com a literatura, pois outros estudos também observaram essa diferença de informação entre os valores especificados no rótulo e os obtidos nas análises laboratoriais ${ }^{9-11}$. Um estudo realizado no município de São Paulo avaliou a concentração de flúor em águas minerais e comparou com as informações fornecidas no rótulo, sendo que a maior parte das amostras analisadas apresentou valores acima dos discriminados nas embalagens. Entretanto, apenas uma marca de água mineral apresentou concentração maior que a recomendada no Brasil para consumo humano ${ }^{11}$.

Há um crescente consumo de água mineral no Brasil $^{8-10}$ e em outros países ${ }^{12,13}$. Esse fato ocorre, provavelmente, pela preferência por bebidas saudáveis e livres de impurezas ${ }^{10}$. Dessa forma, os critérios estabelecidos pelo Ministério da Saúde para o padrão de potabilidade da água de consumo humano devem ser aplicados para as águas minerais envasadas, em que o valor máximo permitido (VMP) de flúor é de $1,5 \mathrm{mg} / \mathrm{L}^{14}$, esse VMP é adotado pela maioria dos países ${ }^{5}$. No presente estudo, nenhuma das marcas comerciais avaliadas excederam a concentração máxima permitida de íons de flúor.

No Brasil, a melhor faixa de concentração de flúor, que fornece máximo benefício na prevenção de cárie dentária e baixo risco de produzir fluorose dentária, é de 0,65 a $0,94 \mathrm{mg} / \mathrm{L}$ de F, com variações de acordo com diferenças nas temperaturas médias anuais $^{6}$. No Rio Grande do sul, o teor de concentração ideal de flúor na água para consumo humano é de $0,8 \mathrm{mg} / \mathrm{L}$, considerando dentro do padrão de potabilidade as águas que apresentarem a concentração de fluoreto variando de 0,6 a $0,9 \mathrm{mg} / \mathrm{L}^{5,6}$. En- tretanto, na Resolução RDC no 274 , de 22 de setembro de 2005, que estabelece o Regulamento Técnico Para Águas Envasadas e Gelo, esses valores de concentração de flúor ideais para a prevenção de cárie dentária não são delimitados. A referida resolução apenas considera como água mineral fluoretada quando o produto contiver mais que $1 \mathrm{mg} / \mathrm{L}$ de fluoreto, e que o produto não é adequado para lactentes e crianças com até 7 anos de idade quando contiver mais que $2 \mathrm{mg} / \mathrm{L}$ de fluoreto ${ }^{15}$.

A subdosagem do teor de flúor nas águas não apresenta potencial anticariogênico ${ }^{4,11}$. Neste estudo, apenas uma marca analisada não atingiu a concentração adequada de flúor para a prevenção de cárie dentária. A literatura tem apontado que as águas minerais envasadas vendidas no Brasil geralmente apresentam o teor de flúor insuficiente para fornecer qualquer efeito preventivo em termos de controle de cárie ${ }^{9}$. Situação semelhante é encontrada em outros países, como Austrália e Reino Unido, em que as águas minerais envasadas também registraram níveis de flúor abaixo do necessário para prevenir a cárie dentária ${ }^{12,13}$.

Além disso, existe uma preocupação com os efeitos adversos da sobredosagem do flúor que levam à fluorose dentária durante a fase de desenvolvimento dentário ${ }^{4,10,16}$. As águas minerais Sarandi, Fonte Ijuí e Versant gaseificadas e não gaseificadas apresentaram, em seus rótulos, os valores de concentração de fluoreto acima do valor ideal para prevenção da cárie. Porém, após as análises laboratoriais apenas as águas Sarandi gaseificada e não gaseificada e Fonte Ijuí não gaseificada confirmaram os valores de concentração de flúor acima do ideal para a prevenção da cárie. A água mineral Charrua gaseificada, no seu rótulo, apresentava valor abaixo do ideal para a prevenção de cárie $(0,39 \mathrm{mg} \mathrm{F}-/ \mathrm{L})$, entretanto, na análise laboratorial apresentou um valor pouco acima do ideal $(0,92 \mathrm{mg} \mathrm{F}-/ \mathrm{L})$. As altas concentrações de flúor verificadas em algumas marcas de águas minerais associadas ao aumento de seu consumo são preocupantes, pois podem constituir um fator de risco para a ocorrência de fluorose dentária em crianças menores de 8 anos de idade ${ }^{5,11}$.

Por fim, este estudo apresenta como limitação o fato de os resultados servirem especificamente para o controle da concentração de flúor nas águas minerais envasadas e comercializadas no Rio Grande do Sul, pois não existe uma legislação que defina a quem cabe a responsabilidade de avaliação sistemática dos referidos teores, o que dificulta a comparação com diferentes locais, onde existem leis que estabelecem os níveis de flúor nas águas minerais envasadas e comercializadas e os setores responsáveis pela avaliação dos níveis de flúor. 


\section{Conclusão}

Estratégias de controle dos teores de flúor para as águas minerais devem ser criadas, para que haja uma padronização das concentrações adequadas, proporcionando maior benefício para a saúde bucal com o mínimo de risco para a população. Sugere-se que, em diferentes momentos, sejam reimpressos os rótulos das marcas, equalizando essas divergências entre os rótulos provavelmente antigos e as últimas medidas, visto que a concentração de flúor pode variar conforme variações no lençol freático da fonte mineral.

\section{Abstract}

Objective: quantify the fluoride level in carbogaseous and non-carbogaseous mineral waters bottled in the state of Rio Grande do Sul, Brazil, as well as to compare the data with the information described on the package labels. Materials and method: five brands of mineral water were analyzed. Standard/sample values and Tisab buffer were used in a ratio of $1: 1$, and the samples were read in duplicates. The carbogaseous samples were shaken with a magnetic rod to eliminate the carbon dioxide. For fluoride determination, a specific ion analyzer was used, as well as a fluoride ion-selective electrode, single-junction $\mathrm{Ag} / \mathrm{AgCl}$ reference electrode. Results: fluoride concentrations ranging from $0.13 \mathrm{mg} \mathrm{F} / \mathrm{L}$ to $1.31 \mathrm{mg} \mathrm{F} / \mathrm{L}$ were found, with differences between the values specified in the labels of the mineral water brands evaluated and the laboratory analyses of the present investigation. The values of two brands of mineral water with fluoride analyzed in the study were high, considering the reference values (0.6-0.8 mg F-/L), and one brand did not present values of preventive action against dental caries (below $0.6 \mathrm{mg} \mathrm{F}-\mathrm{L}$ ). Conclusion: there is a divergence between the values of fluoride ions measured and those reported on the labels, which requires a better surveillance system for controlling fluoride levels in the mineral waters offered to the population of the state of Rio Grande do Sul, Brazil, considering the benefits of mineral water consumption to prevent caries levels in the population.

Keywords: Mineral waters. Fluoridation. Health surveillance.

\section{Referências}

1. ADA, Reports. Position of the American Dietetic Association: the impact of fluoride on dental health. J Am Diet Assoc 1989; 89(7):971-4.

2. Cury JA, Tenuta LM. How to maintain a cariostatic fluoride concentration in the oral environment. Adv Dent Res 2008; 20(1):13-6.

3. O'Mullane DM, Baez RJ, Jones S, Lennon MA, Petersen PE, Rugg-Gunn AJ, et al. Fluoride and Oral Health. Comm Dent Health 2016; 33(2):69-99.

4. Ramires I, Buzalaf MAR. A fluoretação da água de abastecimento público e seus benefícios no controle da cárie dentária - cinqüenta anos no Brasil. Ciênc Saúde Colet 2007; 12(4):1057-65.
5. Frazão P, Peres MA, Cury JA. Qualidade da água para consumo humano e concentração de fluoreto. Rev Saúde Pública 2011; 45(5):964-73.

6. Brito CSD, Garbin RR, Mussi A, Rigo L. Vigilância da concentração de flúor nas águas de abastecimento público na cidade de Passo Fundo - RS. Cad Saúde Colet 2016; 24(4):452-9.

7. Maraver F, Vitoria I, Almerich-Silla JM, Armijo F. Fluoride content of bottled natural mineral waters in Spain and prevention of dental caries. Aten Primaria 2015; 47(1):15-24.

8. Ramires I, Grec RH, Cattan L, Moura PG, Lauris JR, Buzalaf MA. Evaluation of the fluoride concentration and consumption of mineral water. Rev Saúde Pública 2004; 38(3):459-65.

9. Costa LNBDS, Rebelo MAB. Evaluation of the fluoride concentration in mineral water and guaraná-based soft drinks. In: Manaus, Amazonas. Avaliação da concentração de flúor em águas minerais e refrigerantes à base de guaraná comercializados em Manaus-AM. Rev Odonto Ciênc 2009; 24(3):240-3.

10. Villena RS, Borges DG, Cury JA. Avaliação da concentração de flúor em águas minerais comercializadas no Brasil. Rev Saúde Pública 1996; 30(6):512-8.

11. Grec RH, de Moura PG, Pessan JP, Ramires I, Costa B, Buzalaf MA. Fluoride concentration in bottled water on the market in the municipality of Sao Paulo. Rev Saúde Pública 2008; 42(1):154-7.

12. Mills K, Falconer S, Cook C. Fluoride in still bottled water in Australia. Aust Dent J 2010; 55(4):411-6.

13. Zohouri FV, Maguire A, Moynihan PJ. Fluoride content of still bottled waters available in the North-East of England, UK. Br Dent J 2003; 195(9):515-8.

14. Brasil. Ministério da Saúde. Portaria 1469, de 29 de dezembro de 2000. Estabelece os procedimentos e responsabilidades relativos ao controle e vigilância da qualidade da água para consumo humano e seu padrão de potabilidade, e dá outras providências; Brasília: Ministério da Saúde; 2000.

15. Brasil. Agência Nacional de Vigilância Sanitária. Resolução $\mathrm{RDC}^{\circ} \mathbf{2} 274$, de 22 de setembro de 2005. Regulamento técnico para águas envasadas e gelo. Brasília: Anvisa; 2005.

16. Carvalho RBD, Medeiros UVD, Santos KTD, Pacheco Filho AC. Influência de diferentes concentraçoes de flúor na água em indicadores epidemiológicos de saúde/doença bucal. Ciênc Saúde Colet 2011; 16(8):3509-18.

\section{Endereço para correspondência:}

Alexandre Emidio Ribeiro Silva, Universidade Federal de Pelotas Rua Gonçalves Chaves, 3172/202 96015-560, Pelotas, RS, Brasil E-mail: aemidiosilva@gmail.com 